\title{
Barriers to Purchasing Narcan® in Georgia: A Survey of Pharmacy Staff
}

Thomas E. Griner, PhD, JD, MPP ${ }^{1}$, Sheryl Strasser, PhD, MPH, MSW, MCHES ${ }^{2}$, Stacie P. Kershner, JD ${ }^{3}$, Ashli A. Owen-Smith, $\mathrm{PhD}, \mathrm{SM}^{4}$, and Matthew J. Hayat, $\mathrm{PhD}^{5}$

${ }^{1}$ Law Office of Thomas E. Griner, LLC; ${ }^{2}$ School of Public Health, Georgia State University; ${ }^{3}$ Center for Law, Health \& Society, Georgia State University College of Law; ${ }^{4}$ Health Management \& Policy, School of Public Health, Georgia State University; and ${ }^{5}$ Department of Population Health Sciences, School of Public Health, Georgia State University

Corresponding Author: Thomas E. Griner • Law Office of Thomas E. Griner, LLC • 231 Washington Avenue, Marietta, GA, 30060 • Telephone: (770)377-7635

•Email: tom@thomasgrinerlaw.com, tgriner2@gsu.edu

\section{ABSTRACT}

Background: In Georgia, recent measures have expanded public access to naloxone-containing products like Narcan ${ }^{\circledR}$ to combat opioid-related overdose deaths. Although laypersons may legally purchase naloxone products without a prescription for use during opioid-related overdose events, barriers may remain.

Methods: We conducted an anonymous telephone survey to investigate three potential barriers to purchasing naloxone (Narcan $\left.{ }^{\circ}\right)$ in Georgia: availability, price, and working knowledge of legal requirements among pharmacy representatives. We surveyed pharmacy representatives in select Georgia counties with high volumes or high rates of poisoning deaths compared with other counties. We also compared responses among chain and non-chain representatives. Descriptive statistics are presented concerning the availability, price, and required documentation to purchase Narcan ${ }^{\circledR}$.

Results: Representatives from all 120 pharmacies contacted completed the survey, comprising $6.8 \%$ of eligible pharmacies. Availability of Narcan ${ }^{\circledR}$ varied among counties categorized by poisoning deaths: High Rate Counties (50\%; $\left.\mathrm{n}=40\right)$, High Volume Counties $(66 \% ; n=38)$, and Comparison Counties $(64 \%, n=42)$. Narcan ${ }^{\circledR}$ was more available in chain pharmacies $(76.7 \%$; $n=73)$ than in non-chain pharmacies $(34.0 \% ; n=47)$. Mean prices for Narcan ${ }^{\circledR}$ were similar among county type: High Volume $(\$ 131.46)$; High Rate (\$134.19); and Comparison (\$124.50). However, the mean price was much lower in chain versus non-chain pharmacies (\$120.91 vs. \$149.72). Representatives in chain pharmacies were more likely to state that a prescription was not required to purchase $\operatorname{Narcan} 囚(58.9 \%$ vs. $30.0 \%)$.

Conclusions: In Georgia, barriers related to availability, price, and dispensing requirements for Narcan ${ }^{\circledR}$ persist, decreasing the likelihood of purchase by those who may need a safe, easily administered form of naloxone. Narcan ${ }^{\circledR}$ was generally more available and cost less in chain pharmacies. Representatives in non-chain pharmacies were more likely to require a non-legally necessary prescription to sell Narcan ${ }^{\circledR}$. Training/intervention opportunities targeting pharmacy staff may help increase layperson access to naloxone products and could ultimately prevent opioid-related overdose deaths.

Keywords: Naloxone access, pharmacy practice, opioid overdose reversal, public health law, Narcan ${ }$.

\section{INTRODUCTION}

Reports of the nation's drug overdose crisis are ubiquitous, with opioid overdoses becoming a national public health priority in recent years. One strategy that has received wide support in combating opioid overdose deaths is to make naloxone products like Narcan $\AA$, (Naloxone HCL, Narcan - ADAPT Pharma) an opioid antagonist drug, more available to those who may witness an overdose or come into contact with overdose victims. Naloxone is a therapeutic drug overdose reversal agent commonly used by medical professionals to counteract the effects of heroin and other opiates (Sporer \& Kral, 2007). Recent measures have been adopted in nearly every state to make the dissemination of naloxone to the public easier (Xu et al., 2018). The United States Surgeon General supports the increased availability of naloxone products to the public
(Office of the Surgeon General, 2018) as does the Georgia Department of Public Health (Georgia Department of Public Health, 2018). A growing body of academic literature underscores the benefits of increased public access to naloxone (Cressman et al., 2017; Davis et al., 2013; Galea et al., 2006; Meyerson et al., 2018; Xu et al., 2018).

Pharmacists may represent an underutilized resource in promoting and disseminating naloxone products to those in a position of caring for overdose victims (Sisson et al., 2019). Although pharmacists have knowledge of pharmaceutical products and contact with the public, several barriers seem to limit the potential benefits of more widely disseminating naloxone products to the public (Green et al., 2015; Rudolph et al., 2018). A survey among pharmacists in West Virginia reported that only $20.4 \%$ were comfortable 
selling naloxone without a prescription (Thornton et al., 2017). A Pennsylvania survey of pharmacy representatives revealed that naloxone was stocked in only $45 \%$ of stores contacted, prices ranged from $\$ 50$ to $\$ 4000$, and fewer than two-thirds (64\%) could correctly answer questions about Pennsylvania's naloxone standing order, which allows the purchase of naloxone products without a prescription from a medical provider. Further, staff working in national pharmacies in Pennsylvania were significantly more accurate than counterparts in smaller pharmacies in correctly answering whether a prescription was required to obtain naloxone (Graves et al., 2018). A separate study that focused on Philadelphia showed that naloxone was stocked in only $34.2 \%$ of that city's pharmacies but $61.5 \%$ of pharmacies contacted would sell naloxone without a prescription. However, naloxone was much more available and likely to be sold without a prescription in chain stores than in independent stores and naloxone was less likely to be available in districts with elevated rates of opioid overdose deaths. Prices ranged from $\$ 119-150$, and were higher in independent pharmacies and in planning districts with elevated rates of opioid overdose deaths (Guadamuz et al., 2019). Results from a survey of Indiana community pharmacists following implementation of a state-issued standing order allowing naloxone dispensation showed that, while $58.1 \%$ stocked naloxone, only $23.6 \%$ had actually dispensed it. Chain pharmacies in Indiana were 3.2 times as likely to stock naloxone as non-chain pharmacies (Meyerson et al., 2018). Stone and colleagues demonstrated that only $31 \%$ of pharmacies contacted in Georgia had naloxone available for same-day purchase, and chain community pharmacies were significantly more likely to carry naloxone than independent pharmacies (45\% vs. $24 \%$ ). Further, areas with high opioid mortality were more likely to have naloxone than areas with low mortality rates (38\% vs. 24\%) (Stone et al., 2019). Nguyen and colleagues surveyed pharmacists working in rural Georgia counties and reported that $54.7 \%$ stocked Narcan $\AA$, and among those who did not stock Narcan $\AA, 75 \%$ referred the caller to a chain store. In those rural Georgia counties, the mean cash price of $\operatorname{Narcan}{ }^{\circledR}$ was $\$ 131.04$, and $47.1 \%$ of pharmacists correctly answered that a prescription was unnecessary to purchase Narcan ${ }^{\circledR}$ (Nguyen et al., 2020).

Such research suggests that low or inconsistent stocking, high prices, and a lack of knowledge of laws surrounding naloxone products limit pharmacy representatives from becoming more effective resources in battling opioid-related overdoses.

Like most states, Georgia policymakers have acted to increase layperson access to naloxone through standing orders executed on January 12, 2017, June 29, 2018, and March 6, 2019. The purpose is stated clearly:

"The purpose of this Standing Order is to facilitate the widest possible availability of naloxone among the residents of this State, to ensure that family members, friends, co-workers, first responders, schools, pain management clinics, harm reduction organizations, and any other persons or entities ("Eligible Persons or Entities") are in a position to provide assistance to a person experiencing an opioid-related overdose through the timely administration of the opioid antagonist naloxone."

(Kathleen E. Toomey, M.D., M.P.H., 2019)

The Georgia General Assembly enacted O.C.G.A. § 26-4-116.2 (f), requiring that "Every pharmacy in this state shall retain a copy of the standing order issued under Code Section 31-1-10" (Effective July 1, 2017). Moreover, Georgia's Dangerous Drug Act was amended (by Emergency Rule on Naloxone 480-34-0.31-.11 effective December 14, 2016 and by statutory amendment effective July 1,2017 ) to exempt naloxone from the list of drugs that require a physician's prescription, if the naloxone is used for drug overdose prevention and supplied by a dispenser in a specified manner (O.C.G.A. § 16-13-71, 2017). Thus, at the time of this study, Georgia pharmacists were authorized to dispense naloxone products without a prescription from a medical provider to address potential opioid overdoses.

This study examines three specific barriers related to naloxone access in Georgia: availability, price, and working knowledge among pharmacy representatives that a prescription is no longer necessary to purchase naloxone. We examine whether these barriers differ in counties that either have high poisoning death rates or high poisoning death totals when compared with controls, and whether such barriers vary by status as a chain or non-chain pharmacy. We use Narcan ${ }^{\circledR}$ as a proxy for all naloxone products, and poisoning deaths generally as a proxy for drug poisoning deaths. We are not aware of any study that has explored all three of these barriers to citizen naloxone purchase from pharmacies in Georgia in the manner described. Further, few studies have specifically examined whether such barriers differ within a state, such as in counties with high rates or volumes of drug poisoning deaths.

\section{METHODS}

We present descriptive statistics from an anonymous telephone survey of pharmacy representatives concerning three potential barriers to purchasing naloxone in Georgia: availability, price, and working knowledge that a prescription is no longer a requirement to purchase naloxone. We further examine whether such potential barriers differ in counties that either have high poisoning death rates or high poisoning death totals when measured against comparison counties, and whether such barriers vary by status as a chain or non-chain pharmacy. The Georgia State University Institutional Review Board designated this study as not Human Subject Research, thereby exempting it from review.

Using the Centers for Disease Control and Prevention Web-based Injury Statistics Query and Reporting System (WISQARS), we generated an age-adjusted map (2000 as the standard year) of poisoning deaths of all types in Georgia at the county level (Centers for Disease Control and Prevention \& National Center for Injury Prevention and Control, Statistics, Programming and Economics Branch, 2013). Overall, Georgia exhibited a lower annualized, 
age-adjusted poisoning death rate for 2008-2014 than the nationwide average (11.82 versus 14.45 deaths/100,000). Of 159 counties in Georgia, 76 provided data on poisoning deaths during 2008-2014. However, 42 Georgia counties reported higher poisoning death rates than the nationwide average. Certain metro counties, although not having death rates that exceeded the national average, contributed a large volume of poisoning deaths to the total number of deaths.

We divided these 76 counties with reported data into three categories:

1) "high death rate counties" $(n=42)$ experienced poisoning death rates higher than the nationwide average from 2008 - 2014;

2) "high death volume" counties $(n=20)$ experienced more than 100 total annual deaths for the same period; and

3) "comparison counties" $(n=20)$ are the remaining counties in Georgia for which poisoning death data were available.

Carroll, Bartow, Paulding, Whitfield, Floyd, and Richmond Counties $(n=6)$ meet the conditions for inclusion in either the high death rate or the high death volume categories. These 6 "dual qualifying" counties are classified as high death rate counties rather than high death volume counties in this study for better balance among pharmacy locations across categories (See Appendix: Figure 1 and Table 3). Comparisons made below support the inclusion of these dual qualifying counties within the high rate county category rather than the high volume county category.

A list of pharmacies that service each county seat was obtained from Superpages.com, an online telephone and address directory that provides pharmacy contact information by city (superpages.com, n.d.). Each pharmacy was numbered, and a random sequence generator used to designate pharmacies for contact. A total of 120 pharmacies were randomly selected without replacement and contacted by telephone from October through December, 2018, as follows:

1) high death rate counties (poisoning death rate exceeding 14.45/100,000; $\mathrm{n}=42$ ): 40 pharmacies randomly selected without replacement from 745 pharmacies.

2) high death volume counties (more than 100 poisoning deaths from $2008-2014 ; n=14$ ): 40 pharmacies randomly selected without replacement from 686 pharmacies.

3) comparison counties (neither high death rate nor high death volume; $n=20): 40$ pharmacies randomly selected to provide baseline data from 335 pharmacies.

(See Appendix, Figure 2)

Calls were made anonymously by the lead author. A call script was begun with whomever answered the phone, and continued with subsequent representatives if the first respondent transferred the call (i.e. to a supervisor or pharmacist) until the survey was complete.
Representatives were asked the following questions to test four (4) potential barriers to the acquisition of $\operatorname{Narcan}{ }^{\circledR}$ :

Availability of Narcan ${ }^{\circledR}$ : Do you have Narcan ${ }^{\circledR}$ nasal spray in stock?

Price of Narcan ${ }^{\circledR}$ : How much does it cost?

Awareness that a prescription is not required to

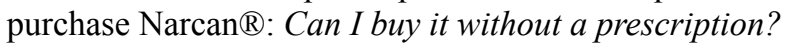
Other barriers: Are there any forms I have to fill out if I want to pay with cash?

\section{RESULTS}

Representatives from all 120 pharmacies contacted for study participation completed the survey (100\% response rate). The sample represented $6.8 \%$ of the total number of pharmacies operating in Georgia $(1,766)$ that were eligible for the study. A final review of pharmacies contacted resulted in two being removed from the high volume category and reclassified as comparison county pharmacies.

\section{Whether $\operatorname{Narcan}{ }^{\circledR}$ was in stock and its price}

In high rate counties, $50 \%$ of pharmacies contacted had Narcan ${ }^{\circledR}$ in stock, compared with $66 \%$ of those in high volume counties and $64 \%$ of those in comparison counties.

The price of $\operatorname{Narcan}{ }^{\circledR}$ in high rate counties averaged \$134.19 (Range: 71.69 to 180.00 ), compared with \$131.46 (Range: 71.69 to 171.95 ) in high volume counties, and $\$ 124.50$ (Range: 65.00 to 201.00) in comparison counties (See Table 1).

\section{Requirements to purchase $\operatorname{Narcan}{ }^{\circledR}$}

Slightly more than half the pharmacy representatives questioned in high rate counties $(55 \%)$ stated that a prescription was not required for purchasing Narcan ${ }^{\circledR}$, compared with $42 \%$ in high volume counties and $45 \%$ in comparison counties. A few pharmacy representatives in each county category either did not know, expressed uncertainty, or refused to answer whether a prescription was required to purchase Narcan ${ }^{\circledR}$ (See Table 1).

\section{"Dual Qualifiers": the six counties that could be categorized as either high volume or high rate counties}

A total of 157 pharmacies were listed in the six counties that could have been included in either the high rate or high volume categories. Eleven (11) pharmacies from these "dual qualifying" counties were among those randomly contacted.

Stock levels of Narcan ${ }^{\circledR}$ in dual qualifying counties $(45 \%$, $5 / 11$ ) were more similar to stocking percentages in the remaining high rate counties $(52 \%, 15 / 29)$ and more dissimilar to percentages in high volume counties $(66 \%$, $25 / 38)$ and comparison counties $(64 \%, 27 / 42)$.

The average price of Narcan ${ }^{\circledR}$ in dual qualifying counties was almost $\$ 11$ more than the price of Narcan ${ }^{\circledR}$ in the remaining high rate counties (the category in which they were assigned) (\$142.12 versus \$131.43) and high volume 
counties ( $\$ 142.12$ versus $\$ 131.46$ ). In contrast, the price of Narcan ${ }^{\circledR}$ in dual qualifying counties was almost $\$ 18$ higher than in comparison counties ( $\$ 142.12$ versus $\$ 124.50)$.

Accuracy in answering the prescription-requirement question among dual qualifying counties $(64 \%, 7 / 11)$ was closer to the remaining high rate counties $(52 \%, 15 / 29)$ than high volume counties $(42 \%, 16 / 38)$, or comparison counties (45\%, 19/42). These comparisons show that dual qualifying counties are generally more similar to the remaining counties in the high rate county category than counties in the high volume county category.

Table 1

Availability, price, and whether prescription required to purchase Narcan ${ }^{\circledR}$ among Georgia counties by county type

\begin{tabular}{|cccc|}
\hline County Type & Narcan ${ }^{\circledR}$ in Stock & $\begin{array}{c}\text { Average Price [Standard } \\
\text { Deviation] (Range) }\end{array}$ & $\begin{array}{c}\text { Prescription not required } \\
\text { to purchase Narcan }{ }^{\circledR}\end{array}$ \\
\hline $\begin{array}{l}\text { High Rate ** } \\
\mathrm{n}=40\end{array}$ & $50 \%$ (1 N.A.) & $\begin{array}{c}134.19[25.03] \\
(71.69-180.00)\end{array}$ & $55 \%$ (2 N.A.) \\
\hline \multicolumn{1}{|c|}{$\begin{array}{c}\text { Dual Qualifiers* } \\
\mathrm{n}=11\end{array}$} & $45 \%$ (1 N.A.) & $\begin{array}{c}142.12[10.83] \\
(129.99-160.00)\end{array}$ & $64 \%$ (1 N.A.) \\
\hline $\begin{array}{l}\text { High Rate w/ Dual } \\
\text { Qualifiers removed } \\
\mathrm{n}=29\end{array}$ & $52 \%$ & $131.43[28.04]$ & $52 \%$ (1.N.A.) \\
\hline $\begin{array}{l}\text { High Volume } \\
\mathrm{n}=38\end{array}$ & $66 \%$ & $\begin{array}{c}131.46[24.70] \\
(71.69-171.95)\end{array}$ & $42 \%$ (5 N.A.) \\
\hline $\begin{array}{l}\text { Comparison } \\
\mathrm{n}=42\end{array}$ & $64 \%$ & $\begin{array}{c}124.50[33.56] \\
(65.00-201.00)\end{array}$ & $45 \%$ (3 N.A.) \\
\hline
\end{tabular}

N.A. means "No Answer" - pharmacy representative(s) refused or could not answer

* Dual Qualifiers are a subset of the High Rate County Type

** Includes Dual Qualifiers

\section{Associations between barriers and chain pharmacy status}

We considered whether barriers may differ among chain pharmacies versus non-chain pharmacies. Here, "chain pharmacies" were defined as brands with more than 4 locations in Georgia (Law Insider, n.d.). The names of chain pharmacies contacted are on file with the lead author. Among those pharmacies randomly selected, chain stores constituted $47.5 \%(19 / 40)$ of those sampled in high rate counties, $68.4 \%(26 / 38)$ of those sampled in high volume counties, and $66.7 \%(28 / 42)$ of those sampled in comparison counties.

Across all three county categories, Narcan ${ }^{\circledR}$ was immediately available for purchase more frequently in chain pharmacies $(76.7 \%)$ than in non-chain pharmacies $(34.0 \%)$. In high rate counties, $68.4 \%$ of chain store pharmacies had Narcan ${ }^{\circledR}$ in stock, compared with $33.3 \%$ of non-chain pharmacies (overall average was 50\%). In high volume counties, $81 \%$ of chain store pharmacies had Narcan ${ }^{\circledR}$ in stock, compared with $33.3 \%$ of non-chain stores (overall average was $66 \%$ ). In comparison counties, $78.5 \%$ of chain stores had $\operatorname{Narcan}{ }^{\circledR}$ in stock versus $35.7 \%$ of non-chain pharmacies (overall average was 64\%).
Overall, prices for Narcan ${ }^{\circledR}$ nasal spray ranged from $\$ 65.00$ to $\$ 201.00$. However, the average chain pharmacy price statewide (\$120.91) was nearly \$30 less expensive than the average non-chain pharmacy price $(\$ 149.72)$, and remained consistently lower across all county categories. In high rate counties (overall average: \$134.19), the average chain store price (\$122.60) was nearly $\$ 26$ lower than the average non-chain pharmacy price $(\$ 148.27)$. In high volume counties (overall average: $\$ 131.46$ ), the average chain store price $(\$ 126.20)$ was $\$ 27$ lower than the average non-chain pharmacy price (\$153.37). In comparison counties (overall average: $\$ 124.50)$, the average chain store price $(\$ 114.48)$ was $\$ 35$ lower than the average non-chain pharmacy price (\$149.55) (See Table 2).

Contrary to current legislation and Georgia's standing order, representatives from nearly one-half of pharmacies contacted stated that a physician's prescription was a requirement for purchasing $\operatorname{Narcan}{ }^{\circledR}(53 / 120)$. Of the remainder, representatives from 57 pharmacies stated that a prescription was not required, and those from 10 non-chain pharmacies either refused or were unable to answer the question. Representatives from chain pharmacies more often stated correctly that a prescription was not required to purchase Narcan $\mathbb{}(58.9 \%$ vs. $30 \%)$. 
Table 2

Availability and price of Narcan ${ }^{\circledR}$ among Georgia counties by county type, stratified by chain store status

\begin{tabular}{|c|c|c|c|}
\hline \multicolumn{3}{|c|}{ Mean Price of Narcan® [Standard Deviation] } & \multirow[t]{2}{*}{ Narcan $\otimes$ in Stock } \\
\hline High Rate Counties & Chain Store & $122.60[25.68]$ & \\
\hline & $\mathrm{n}=19$ & (Range: $71.69-150.00$ ) & $68.40 \%$ \\
\hline \multirow{4}{*}{$\begin{array}{l}\text { Overall: } \\
134.19[25.03]\end{array}$} & \multicolumn{3}{|c|}{ (2 N.A.) } \\
\hline & Non-chain Store & $148.27[15.64]$ & \multirow{3}{*}{$33.30 \%$} \\
\hline & \multirow[t]{2}{*}{$\mathrm{n}=\mathbf{2 1}$} & (Range: $117.00-180.00)$ & \\
\hline & & (7 N.A.) & \\
\hline \multirow[t]{2}{*}{ High Volume Counties } & Chain Store & $126.20[25.19]$ & \multirow{3}{*}{$81 \%$} \\
\hline & $\mathbf{n}=\mathbf{2 6}$ & (Range: $71.69-171.95$ ) & \\
\hline \multirow{4}{*}{$\begin{array}{l}\text { Overall: } \\
131.46[24.70]\end{array}$} & \multicolumn{2}{|r|}{ (1 N.A.) } & \\
\hline & Non-chain Store & $153.37[4.71]$ & \multirow{3}{*}{$33.30 \%$} \\
\hline & $\mathrm{n}=12$ & (Range: $150.00-161.25$ ) & \\
\hline & & (6 N.A.) & \\
\hline \multirow[t]{2}{*}{ Comparison Counties } & Chain Store & $114.48[32.98]$ & \multirow{3}{*}{$78.50 \%$} \\
\hline & $\mathbf{n}=\mathbf{2 8}$ & (Range: $65.00-171.95$ ) & \\
\hline \multirow{4}{*}{$\begin{array}{l}\text { Overall: } \\
124.50[33.56]\end{array}$} & \multicolumn{2}{|r|}{ (3 N.A.) } & \\
\hline & Non-chain Store & $149.55[19.46]$ & \multirow{3}{*}{$35.70 \%$} \\
\hline & $\mathrm{n}=14$ & (Range: 131.59-201.00) & \\
\hline & & (4 N.A.) & \\
\hline \multirow[t]{2}{*}{ Statewide } & Chain Store & $120.91[28.52]$ & \multirow{3}{*}{$76.70 \%$} \\
\hline & $n=73$ & (Range: $65.00-171.95$ ) & \\
\hline Overall: & & (6 N.A.) & \\
\hline \multirow[t]{3}{*}{$129.82[28.45]$} & Non-chain Store & $149.72[15.32]$ & \multirow{3}{*}{$34.00 \%$} \\
\hline & $\mathrm{n}=\mathbf{4 7}$ & (Range: $117.00-201.00$ ) & \\
\hline & & (17 N.A.) & \\
\hline
\end{tabular}

N.A. means "No Answer" - pharmacy representative(s) refused or could not answer

\section{DISCUSSION}

Although drug poisoning deaths in Georgia are generally lower than in the rest of the U.S. (2016: 13.28 versus $19.73 / 100,000)$, they are not distributed evenly within the state (Centers for Disease Control and Prevention \& National Center for Injury Prevention and Control, Statistics, Programming and Economics Branch, 2013). In 2016, for instance, Georgia's metropolitan areas, which contain $83 \%$ of the state's population, suffered higher drug poisoning death rates than non-metropolitan areas (13.48 versus 12.32/100,000) (Georgia Department of Public Health, 2017). Drug overdose death rates in Georgia have also increased in recent years. From 2010 to 2017, Georgia's overall drug poisoning deaths rose by $52 \%$, while the population increased by $7.6 \%$ (United States Census Bureau, 2018). The percentage of opioid-related deaths among all drug overdose deaths increased from $40.1 \%$ in 2010 to $64.4 \%$ in 2017 (Georgia Department of Public Health, 2017).

This study sought to examine potential barriers that may hinder laypersons from purchasing Narcan ${ }^{\circledR}$ from pharmacies in Georgia. Analyzing how these barriers may differ among counties with higher rates or volumes of poisoning deaths and among chain and non-chain pharmacies may help policy makers facilitate the widest possible availability of naloxone among the residents of Georgia, which is the stated goal of the standing order.

As noted, pharmacies in different county categories had similar stocking rates of Narcan ${ }^{\circledR}(50-66 \%)$. This finding is consistent with studies that demonstrate that fewer than $67 \%$ of pharmacies in other states stock naloxone. However, Georgia chain store pharmacies had much higher stock rates of Narcan ${ }^{\circledR}$ than non-chain pharmacies $(76.7 \%$ vs. $34.0 \%$ ). Further, the mean price in chain store pharmacies was almost $\$ 30$ lower than in non-chain

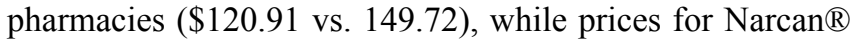
among high rate counties, high volume counties, or comparison counties were more similar (within approximately \$10). Greater stocking rates and lower prices may reflect greater purchasing power, efficiencies in distribution, or shelf space constraints within retail pharmacies.

The mean price of $\operatorname{Narcan} \AA$ statewide $(\$ 129.82)$ is concerning, because it may be too expensive for many potential purchasers to keep on hand in case of overdose. The lack of differences in price among county categories and relatively low stocking rates for such a potentially important product may indicate that high prices, especially in absence of health insurance, have suppressed demand. Further research may focus on Dual Qualifying counties, 
where prices were highest, stock rates were lowest, and representatives most often stated that a prescription was not a requirement to purchase $\operatorname{Narcan} \AA$.

Further research may determine whether naloxone sales differ among county categories in Georgia and whether demand for Narcan $\AA$ or other naloxone products outpaces supply. Determining how often pharmacies reorder Narcan ${ }^{\circledR}$ may suggest actual distribution to potential overdose victims and witnesses to overdose. Also, many consumers may not be aware of the existence or efficacy of Narcan ${ }^{\circledR}$, and thus may not order it from pharmacies. How commercial marketing influences prices and its consequent effects on access to life-saving prevention measures is not well understood and additional investigation may reveal effective ways to address barriers associated with the price of Narcan ${ }^{\circledR}$ (Gupta et al., 2016).

Some differences existed among pharmacy representatives questioned across county type in stating that a physician's prescription was not required for purchasing Narcan $₫$. However, chain store representatives were overwhelmingly more likely than non-chain store representatives to state that a physician's prescription was not required to purchase Narcan ${ }^{\circledR}(58.9 \%$ vs. 30\%). Further research may explore whether different training or levels of experience with Narcan ${ }^{\circledR}$ account for these dissimilarities.

Despite current legal measures designed to increase the availability of naloxone products by obviating the requirement for a doctor's prescription, less than half those contacted stated that a physician's prescription was not required for purchase of $\operatorname{Narcan} \AA$. Among those who accurately stated that a prescription was not required, some mentioned other requirements for purchasing Narcan ${ }^{\circledR}$, such as: verification that opioid medication was prescribed for the potential overdose victim, proof of identification (i.e. driver's license), or the name and address of the purchaser. Some of those who accurately stated that a prescription was not required did not know or were unsure whether such additional requirements were necessary to purchase

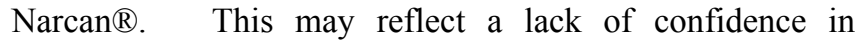
knowledge of the current state of Georgia law, or it may relate more to pharmacy policies. Pharmacies may have certain restrictions and policies governing drug dispensation, even with a prescription, and pharmacists may even refuse to fill a prescription on moral grounds. Pharmacy policies may exist that will impose burdens on the purchase of naloxone, such as requiring a prescription despite the current state of the law or requiring a purchaser to fill out a form that requests personal information. Whether or not non-chain pharmacy policies differ from chain store pharmacy policies surrounding dispensation of Narcan ${ }^{\circledR}$ may be the subject of further research.

Pharmacy policies that require a physician's prescription run counter to the stated goal of Georgia's Standing Order for Prescription of Naloxone for Overdose Prevention, and also the current policy goals of the Georgia General Assembly and of the United States Surgeon General. Existing barriers

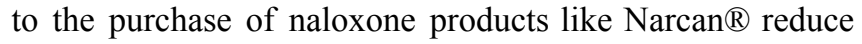

the likelihood that those who may need a safe, easily administered form of naloxone will seek to obtain the product.

\section{Limitations}

This study has several limitations worth noting. The cross-sectional survey design limits conclusions that can be drawn regarding ongoing access, pharmacy representative knowledge, and prices of Narcan $\AA$. We made several efforts to mimic the process that a layperson might use in contacting a pharmacy for naloxone, which may limit the generalizability of the results. The lead author made all phone calls anonymously, following the same script. Other callers could receive different responses. We used an online telephone number service to obtain a list of pharmacies for random selection rather than seek a list of pharmacies from the Georgia Board of Pharmacy, which may have omitted some Georgia pharmacies from inclusion. We began the call sequence with whomever answered the phone rather than initially requesting a pharmacist or supervisor. Often our calls were passed to a pharmacist or person more familiar with $\operatorname{Narcan} \AA$, but it is unknown whether any survey respondent possessed greater or lesser knowledge than others working at each pharmacy contacted. We also must assume that pharmacy representatives honestly and accurately reported information regarding price and availability of Narcan $\AA$. Despite these shortcomings, we believe that the information gathered would reflect the experience that a layperson would have in seeking information directly from local pharmacies in Georgia.

We assumed that Narcan ${ }^{\circledR}$ would serve as a suitable proxy for other naloxone products referenced in Georgia's Standing Order and in recent legislation. Narcan ${ }^{\circledR}$ is a form of naloxone that is intra-nasally administered, requires little training for its use, and is preferable to laypersons over injectable forms of naloxone (Dunn et al., 2018; Freeman et al., 2018). The lower price of $\operatorname{Narcan} \AA$ also makes it a more realistic product for the study of barriers to laypersons in purchasing naloxone. At the time of this study, Evzio ${ }^{\circledR}$, a competing, auto-injectable brand, cost several thousand dollars without a coupon (goodrx.com, 2019). Further, the Georgia Department of Public Health encourages the distribution and use of Narcan ${ }^{\circledR}$ (Georgia Department of Public Health, 2018).

Information on prices obtained does not account for insurance reimbursement. While health insurance may cover all or part of the cost of $\operatorname{Narcan} \AA$, we believe that some purchasers may prefer not to file a claim for insurance reimbursement because of the stigma associated with drug overdose or because of fears that such a claim may result in increased health insurance premiums.

The study design relied in part upon data from the CDC covering 2008-2014. Because this dataset lacked data for drug poisoning deaths, we used poisoning deaths as a proxy for drug poisoning deaths. Further, the background dataset only provided data for 76 out of Georgia's 159 counties. Counties with unreported or suppressed data may differ 
significantly from those counties with reported data. Further research could benefit from updated data reports that were unavailable at the time this study was developed. Counties included and excluded in the study are shown in the Appendix: Table 3.

Narcan ${ }^{\circledR}$ may be available through other routes not considered by this research, such as harm reduction sites. We also assumed that county seats were suitable proxies for other towns within each county. We recognize that a single pharmacy may serve customers from surrounding counties, irrespective of whether we labeled these counties as "high volume", "high rate", or "comparison" counties, and this may blur the distinctions we sought to analyze. Similarly, some Georgia residents may prefer to drive to a neighboring state to purchase Narcan $\AA$, and therefore use a pharmacy not eligible for this study. The sample sizes used for this study, while adequate in the main analysis, resulted in small cell counts when comparisons were drawn across county category and chain store status. Future research may include interventions to better inform, reduce prices, increase the available supply of Narcan ${ }^{\circledR}$ and address the

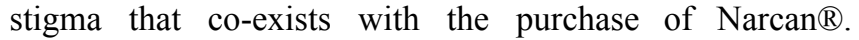
Pharmacy representatives should be trained to provide professional, accurate responses concerning this important opioid-antagonist product.

\section{CONCLUSION}

In Georgia, certain barriers to the purchase of Narcan ${ }^{\circledR}$ exist, making it less likely that those who may need a safe, easily administered form of naloxone will obtain such a product.

Price and availability constraints may prevent or restrain individuals from purchasing naloxone. Further, onerous dispensing requirements may also dissuade individuals from purchasing naloxone. The more barriers that exist, the less likely that individuals will obtain naloxone products to store for emergency use. To the extent that higher prices, lower availability, and pharmacy policies make layperson purchase of naloxone more difficult, fewer will make such a purchase.

\section{Acknowledgements}

Funding Support: This research did not receive any specific grant from funding agencies in the public, commercial, or not-for-profit sectors.

Disclosure: The authors declare no relevant conflicts of interest or financial relationships.

Previous presentation: The preliminary results from this analysis were reported at the American Public Health Association annual meeting in San Diego, California, November 12, 2018.

\section{References}

Centers for Disease Control and Prevention, \& National Center for Injury Prevention and Control, Statistics, Programming and Economics Branch. (2013). Web-based Injury Statistics Query and Reporting System (WISQARS).

www.cdc.gov/injury/wisqars

Cressman, A. M., Mazereeuw, G., Guan, Q., Jia, W., Gomes, T., \& Juurlink, D. N. (2017). Availability of naloxone in Canadian pharmacies:a population-based survey. CMAJ Open, 5(4), E779-E784. https://doi.org/10.9778/cmajo.20170123

Davis, C., Webb, D., \& Burris, S. (2013). Changing Law from Barrier to Facilitator of Opioid Overdose Prevention. The Journal of Law, Medicine \& Ethics, 41(1_suppl), 33-36. https://doi.org/10.1111/jlme.12035

Dunn, K. E., Barrett, F. S., \& Bigelow, G. E. (2018). Naloxone formulation for overdose reversal preference among patients receiving opioids for pain management. Addictive Behaviors, 86, 56-60. https://doi.org/10.1016/j.addbeh.2018.03.011

Freeman, P. R., Hankosky, E. R., Lofwall, M. R., \& Talbert, J. C. (2018). The changing landscape of naloxone availability in the United States, 2011 - 2017. Drug and Alcohol Dependence, 191, 361-364. https://doi.org/10.1016/j.drugalcdep.2018.07.017

Galea, S., Worthington, N., Piper, T. M., Nandi, V. V., Curtis, M., \& Rosenthal, D. M. (2006). Provision of naloxone to injection drug users as an overdose prevention strategy: Early evidence from a pilot study in New York City. Addictive Behaviors, 31(5), 907-912. https://doi.org/10.1016/j.addbeh.2005.07.020

Georgia Department of Public Health. (2017). Opioid Overdose Surveillance Report, Georgia, 2017.

Georgia Department of Public Health. (2018). Naloxone Administration.

https://ph.georgia.gov/sites/dph.georgia.gov/files/Administer\% 20Naloxone.pdf

goodrx.com. (2019). Evzio. https://www.goodrx.com/evzio Graves, R. L., Andreyeva, E., Perrone, J., Shofer, F. S., Merchant, R. M., \& Meisel, Z. F. (2018). Naloxone Availability and Pharmacy Staff Knowledge of Standing Order for Naloxone in Pennsylvania Pharmacies. Journal of Addiction Medicine. https://doi.org/10.1097/ADM.0000000000000492

Green, T. C., Bowman, S., Davis, C., Los, C., McHugh, K., \& Friedmann, P. D. (2015). Discrepancies in addressing overdose prevention through prescription monitoring programs. Drug and Alcohol Dependence, 153, 355-358.

https://doi.org/10.1016/j.drugalcdep.2015.05.009

Guadamuz, J. S., Alexander, G. C., Chaudhri, T., Trotzky-Sirr, R., \& Qato, D. M. (2019). Availability and Cost of Naloxone Nasal Spray at Pharmacies in Philadelphia, Pennsylvania, 2017. JAMA Network Open, 2(6), e195388. https://doi.org/10.1001/jamanetworkopen.2019.5388

Gupta, R., Shah, N. D., \& Ross, J. S. (2016). The Rising Price of Naloxone-Risks to Efforts to Stem Overdose Deaths. New England Journal of Medicine, 375(23), 2213-2215. https://doi.org/10.1056/NEJMp1609578

Kathleen E. Toomey, M.D., M.P.H. (2019). STANDING ORDER FOR PRESCRIPTION OF NALOXONE FOR OVERDOSE PREVENTION. Georgia Department of Public Health. https://dph.georgia.gov/sites/dph.georgia.gov/files/Final\%20201 9\%20standing\%20order\%20naloxone.pdf

Law Insider. (n.d.). https:/www.lawinsider.com/dictionary/chain-pharmacy

Meyerson, B. E., Agley, J. D., Davis, A., Jayawardene, W., Hoss, A., Shannon, D. J., Ryder, P. T., Ritchie, K., \& Gassman, R. (2018). Predicting pharmacy naloxone stocking and dispensing following a statewide standing order, Indiana 2016. Drug and Alcohol Dependence, 188, 187-192.

https://doi.org/10.1016/j.drugalcdep.2018.03.032 
Nguyen, J. L., Gilbert, L. R., Beasley, L., Brooks, J. J., Elliott, J., Smalley, K. B., \& Warren, J. C. (2020). Availability of Naloxone at Rural Georgia Pharmacies, 2019. JAMA Network Open, 3(2), e1921227.

https://doi.org/10.1001/jamanetworkopen.2019.21227

Office of the Surgeon General. (2018). U.S. Surgeon General's Advisory on Naloxone and Opioid Overdose. U.S. Department of Health and Human Services.

https:/www.hhs.gov/surgeongeneral/priorities/opioids-and-addi ction/naloxone-advisory/index.html

O.C.G.A. § 16-13-71, O.C.G.A. § 16-13-71 (2017).

Rudolph, S. E., Branham, A. R., Rhodes, L. A., Hayes, H. "HJ," Moose, J. S., \& Marciniak, M. W. (2018). Identifying barriers to dispensing naloxone: A survey of community pharmacists in North Carolina. Journal of the American Pharmacists Association, 58(4), S55-S58.e3.

https://doi.org/10.1016/j.japh.2018.04.025

Sisson, M. L., McMahan, K. B., Chichester, K. R., Galbraith, J. W., \& Cropsey, K. L. (2019). Attitudes and availability: A comparison of naloxone dispensing across chain and independent pharmacies in rural and urban areas in Alabama. International Journal of Drug Policy, 74, 229-235. https://doi.org/10.1016/j.drugpo.2019.09.021

Sporer, K. A., \& Kral, A. H. (2007). Prescription Naloxone: A Novel Approach to Heroin Overdose Prevention. Annals of
Emergency Medicine, 49(2), 172-177.

https://doi.org/10.1016/j.annemergmed.2006.05.025

Stone, R. H., Hur, S., \& Young, H. N. (2019). Assessment of naloxone availability in Georgia community pharmacies. Journal of the American Pharmacists Association: JAPhA. https://doi.org/10.1016/j.japh.2019.11.003

superpages.com. (n.d.).

Https://www.superpages.com/yellowpages/c-pharmacies/s-ga/cit ies-a/. Retrieved June 24, 2018, from

https://www.superpages.com/yellowpages/c-pharmacies/s-ga/citi es-a/

Thornton, J. D., Lyvers, E., Scott, V. (Ginger) G., \& Dwibedi, N. (2017). Pharmacists' readiness to provide naloxone in community pharmacies in West Virginia. Journal of the American Pharmacists Association, 57(2), S12-S18.e4. https://doi.org/10.1016/j.japh.2016.12.070

United States Census Bureau. (2018). Quick Facts: Georgia. https://www.census.gov/quickfacts/fact/table/GA/POP010210

Xu, J., Davis, C. S., Cruz, M., \& Lurie, P. (2018). State naloxone access laws are associated with an increase in the number of naloxone prescriptions dispensed in retail pharmacies. Drug and Alcohol Dependence, 189, 37-41.

https://doi.org/10.1016/j.drugalcdep.2018.04.020

\section{APPENDIX}

\section{Figure 1}

Georgia Counties Categorized by Poisoning Deaths: 2008 - 2014

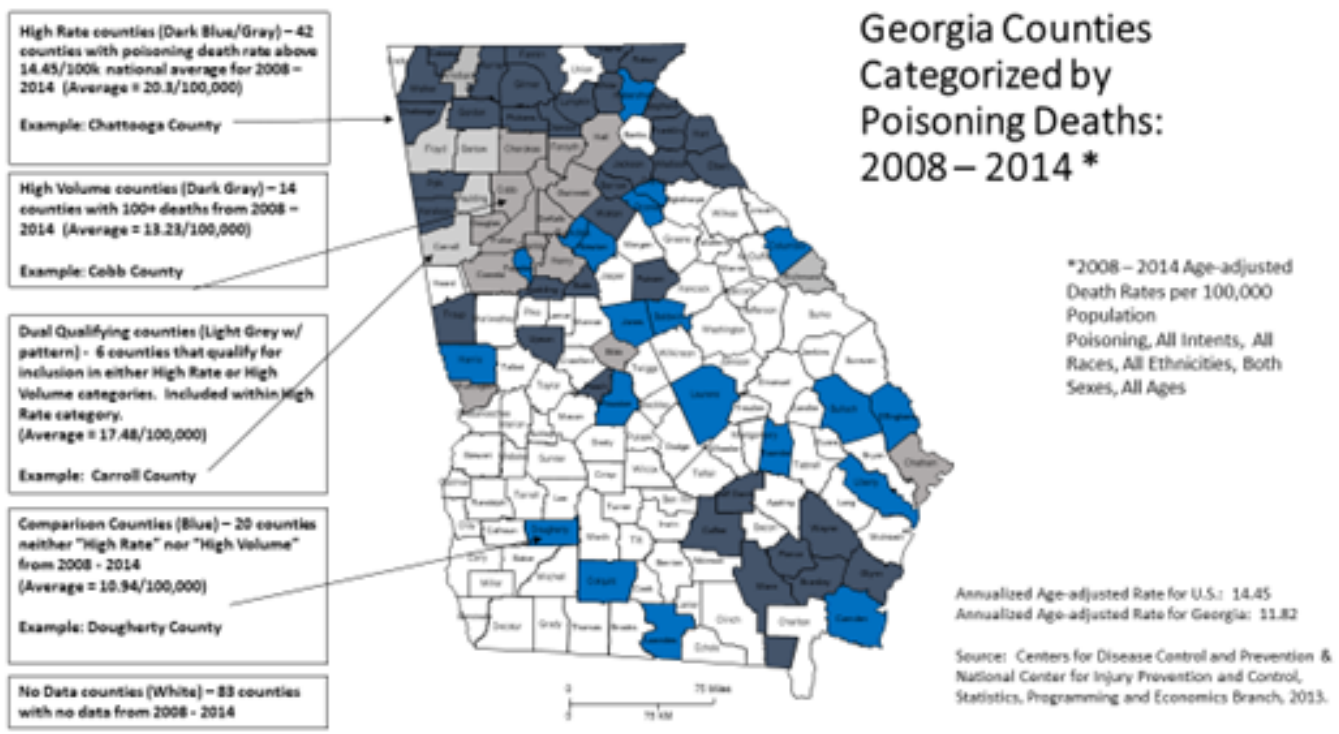


Figure 2

Distribution of Pharmacies Contacted

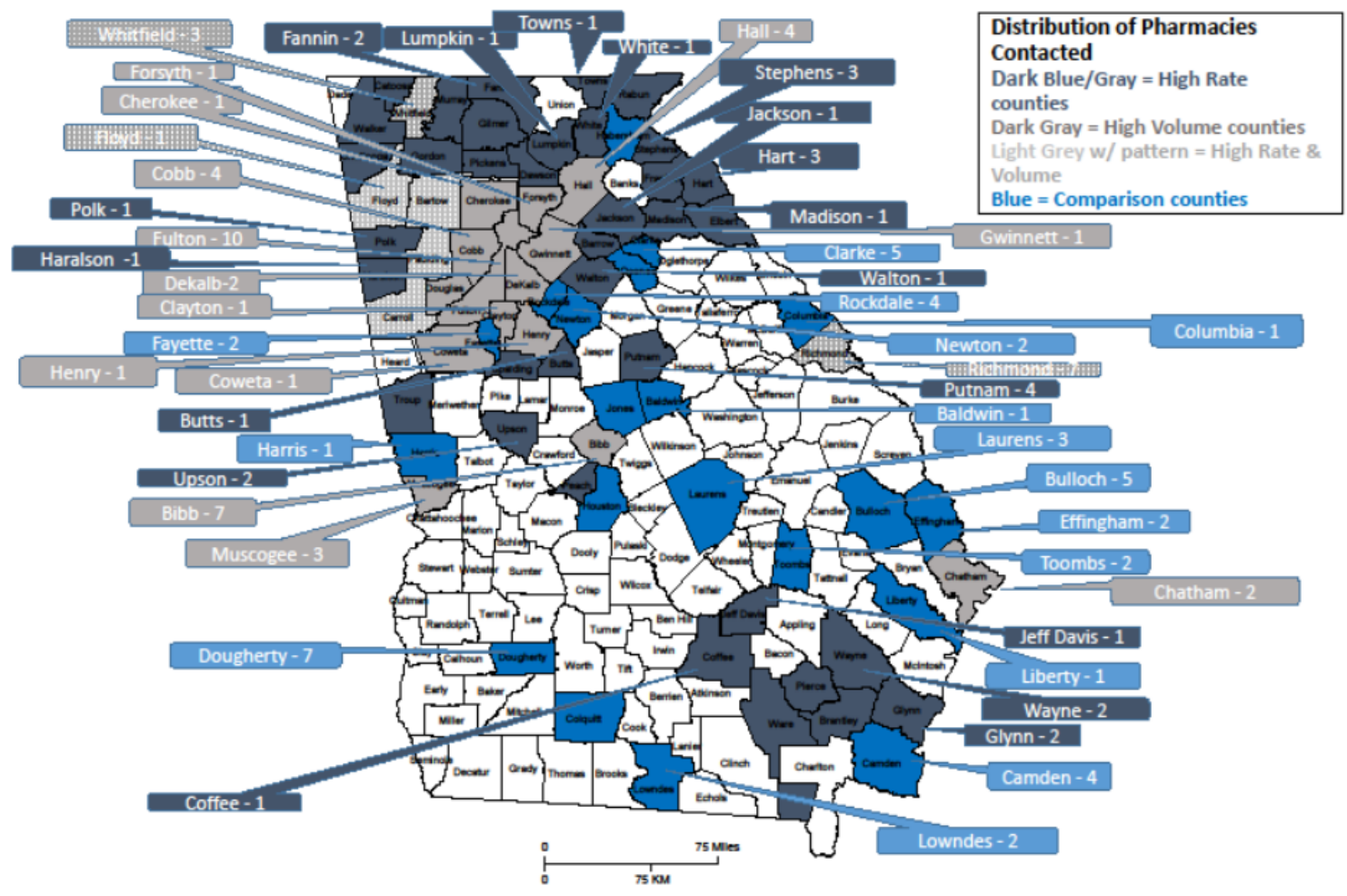


Table 3

Georgia counties by county type

High poisoning death rate counties+ $(\mathbf{n}=\mathbf{4 2})$ : Barrow, Bartow*, Brantley, Butts, Carroll*, Catoosa, Chattooga, Coffee, Dawson, Elbert, Fannin, Floyd*, Franklin, Gilmer, Glynn, Gordon, Haralson, Hart, Jackson, Jeff Davis, Lumpkin, Madison, Murray, Paulding*, Peach, Pickens, Pierce, Polk, Putnam, Rabun, Richmond*, Spalding, Stephens, Towns, Troup, Upson, Walker, Walton, Ware, Wayne, White, Whitfield*

High poisoning death volume counties++ $(\mathbf{n}=\mathbf{1 4})$ : Bartow*, Bibb, Carroll*, Chatham, Cherokee, Clayton, Cobb, Coweta, DeKalb, Douglas, Floyd*, Forsyth, Fulton, Gwinnett, Hall, Henry, Muscogee, Paulding*, Richmond*, Whitfield*

*Dual qualifying counties +++ (n=6): Bartow, Carroll, Floyd, Paulding, Richmond, Whitfield

Comparison counties++++ $(\mathbf{n}=\mathbf{2 0})$ : Baldwin, Bulloch, Camden, Clarke, Colquitt, Columbia, Dougherty, Effingham, Fayette, Habersham, Harris, Houston, Jones, Laurens, Liberty, Lowndes, Newton, Oconee, Rockdale, Toombs

Counties that did not report number of poisoning deaths during time frame (n=83): Appling, Atkinson, Bacon, Baker, Banks, Ben Hill, Berrien, Bleckley, Brooks, Bryan, Burke, Calhoun, Candler, Charlton, Chattahoochee, Clay, Clinch, Cook, Crawford, Crisp, Dade, Decatur, Dodge, Dooly, Early, Echols, Emanuel, Evans, Glascock, Grady, Greene, Hancock, Heard, Irwin, Jasper, Jefferson, Jenkins, Johnson, Lamar, Lanier, Lee, Lincoln, Long, McDuffie, McIntosh, Macon, Marion, Meriwether, Miller, Mitchell, Monroe, Montgomery, Morgan, Oglethorpe, Pike, Pulaski, Quitman, Randolph, Schley, Screven, Seminole, Stewart, Sumter, Talbot, Taliaferro, Tattnall, Taylor, Telfair, Terrell, Thomas, Tift, Treutlen, Turner, Twiggs, Union, Warren, Washington, Webster, Wheeler, Wilcox, Wilkes, Wilkinson, Worth

+ High death rate counties (>14.45/100,000 poisoning deaths for 2008-2014). Dual qualifying counties included in analyses. ++ High death volume counties (>100 poisoning deaths for 2008-2014). Dual qualifying counties not included in analyses.

+++ Dual qualifying counties appear in both high rate and high volume counties because they qualify for inclusion in either category, but are included in high rate county category for analyses.

++++ Comparison counties: 20 remaining counties that reported the number of poisoning deaths but did not meet either high death rate or high death volume county characteristics.

All data downloaded from cdc.com WISQARS 6/28/18

Age-adjusted Death Rates per 100,000 Population; Standard Year $=2000$.

Poisoning, All Intents, All Races, All Ethnicities, Both Sexes, All Ages, Reports include unknown ages.

(C) Thomas E. Griner, Sheryl Strasser, Stacie P. Kershner, Ashli A. Owen-Smith, and Matthew J. Hayat. Originally published in jGPHA (http://www.gapha.org/igpha/) May 15, 2021. This is an open-access article distributed under the terms of the Creative Commons Attribution Non-Commercial No-Derivatives License (http://creativecommons.org/licenses/by/4.0/), which permits unrestricted use, distribution, and reproduction in any medium, provided the original work ("first published in the Journal of the Georgia Public Health Association...") is properly cited with original URL and bibliographic citation information. The complete bibliographic information, a link to the original publication on http://www.gapha.jgpha.org/, as well as this copyright and license information must be included. 